\title{
ECONOMIC EFFECTIVENESS OF OPERATION AND UTILIZATION OF LARGE CONTAINER CARRIERS
}

\begin{abstract}
This paper deals with operational effectiveness of large container carriers transporting standardized transportation units. The calculation is related to costs per one TEU transported. What is a very important factor in maritime transport is the vessel's speed. Speed has a considerable influence on total costs, and that's why this factor is also taken into consideration in the calculation. Besides speed, there is another important factor, i.e. the utilization of the capacity of container ships, and that's why new container ship types (Suezmax and Triple-E) were considered in the calculation. In the conclusion, other factors are stated that are of importance for establishing the utilization and economic effectiveness of the given types of container ships.
\end{abstract}

Keywords: Container, effectiveness, container ship, maritime transport.

\section{Operational effectiveness}

Increasing effectiveness of maritime transport is related to vessel capacity, sailing frequency, idle time in ports, vessel draught limits, speed of service at the port, fuel consumption and cruising speed. It would be very complicated to include all these factors in the calculation. The authors draw on the results published in [1, 2 and 3], where the operational effectiveness of a container ship is illustrated by cost per 1 TEU transported. In this case, cost per TEU is compared in two generations of container ships: Suezmax (10,000-15,000 TEU) and the new EEE class (18,000 TEU).

Besides the ship construction, which was also taken into consideration in these two types of ships, fuel consumption was compared. Fuel consumption of container ships depends on the type of the ship and cruising speed; the consumption growing exponentially at speeds higher than 14 knots $(26 \mathrm{~km} / \mathrm{h})$. That's why the costs per 1 TEU transported were calculated both for normal speed (20-25 knots; $37-46.3 \mathrm{~km} / \mathrm{h}$ ), which is an optimum speed for container ships, at which the engines operate most efficiently (most container ships are designed for a transportation speed of about 24 knots) and for slow steaming speed (18-20 knots; $33.3-37 \mathrm{~km} / \mathrm{h}$ ), where the engines operate below their speed capacity to ensure lower fuel consumption at the expense of a longer shipping time (it is used in ULCV, EEE container ships, which due to their large capacity require a more efficient drive to overcome the great resistance of the hull).

Operational effectiveness of large container ships was calculated and illustrated on an example comparing two types of container ships: Suezmax and the new Triple-E class generation
[4 and 5]. Effectiveness was compared on the example of the Shanghai-Rotterdam-Shanghai route, which is used extensively and provides realistic data for the example calculation. Besides the one-way Shanghai-Rotterdam and Rotterdam-Shanghai routes, values for the Shanghai-Rotterdam-Shanghai cruise are also provided (see Table 1).

The calculation of cost per one TEU transported $\left[\mathrm{N}_{\mathrm{TEU}}\right]$ was based on the following relation (1):

$N_{\text {TEU }}=\frac{(t * c * b)+\sum_{1}^{n} p+T_{S} N_{d} * t}{\left(k * u_{E, W}\right)}[U S D / T E U]$

where

t...cruise duration in days on the Shanghai-Rotterdam-Shanghai route at normal speed and slow steaming speed for the individual vessels [day],

c...fuel consumption (mazout) in tons per day [t/day],

n...number of calls at ports [number],

$p(1-n) \ldots$ port charge amount (disbursement) per day for the given vessel type in individual ports [USD],

b... current price of bunker fuel [USD / metric ton],

$\mathrm{T}_{\mathrm{s}} \ldots$ tolls, Suez Canal transit charges depending on the vessel's parameters [USD],

$\mathrm{N}_{\mathrm{d}}$...the vessel's daily operating costs besides fuel consumption [USD],

k... cargo capacity available in TEU, taking into account unified weight [12 t/TEU],

$\mathrm{u}_{\mathrm{E}} \ldots$ cargo capacity utilization factor in the eastern direction [-],

$\mathrm{u}_{\mathrm{w}}$...cargo capacity utilization factor in the western direction [-].

\footnotetext{
* Jaromir Siroky, Hana Vohankova

Department of Transport Technology and Control, Jan Perner Transport Faculty, University of Pardubice, Czech Republic

E-mail: jaromir.siroky@upce.cz
} 
Calculation of unit costs per 1 TEU transported

Table 1

\begin{tabular}{|c|c|c|c|c|c|c|c|c|c|}
\hline Parameter & $t$ & $c$ & $b$ & $\sum_{p}^{n 1}$ & $u$ & $k$ & $T$ & $N_{d}$ & $N_{T E U}$ \\
\hline \multicolumn{10}{|c|}{ Normal speed, Shanghai-Rotterdam route } \\
\hline Suezmax & 24.6 & 225 & 618 & 449,010 & 0.85 & 13,114 & 263,825 & 14,500 & 379.0 \\
\hline Triple E & 26.0 & 285 & 618 & 632,508 & 0.75 & 18,000 & 343,100 & 18,000 & 427.7 \\
\hline \multicolumn{10}{|c|}{ Normal speed, Rotterdam-Shanghai } \\
\hline Suezmax & 34.5 & 225 & 583 & 523,271 & 0.8 & 13,114 & 263,825 & 14,500 & 528.9 \\
\hline Triple E & 25.8 & 285 & 583 & 463,704 & 0.6 & 18,000 & 343,100 & 18,000 & 482.9 \\
\hline \multicolumn{10}{|c|}{ Normal speed, Shanghai-Rotterdam-Shanghai } \\
\hline Suezmax & 59.1 & 225 & 600 & 972,281 & 0.825 & 13,114 & 263,825 & 14,500 & 906.5 \\
\hline Triple E & 51.8 & 285 & 600 & $1,096,212$ & 0.675 & 18,000 & 343,100 & 18,000 & 896.0 \\
\hline \multicolumn{10}{|c|}{ Slow speed, Shanghai-Rotterdam } \\
\hline Suezmax & 28.8 & 120 & 618 & 449,010 & 0.85 & 13,114 & 263,825 & 14,500 & 269.4 \\
\hline Triple E & 30.6 & 150 & 618 & 632,508 & 0.75 & 18,000 & 343,100 & 18,000 & 297.8 \\
\hline \multicolumn{10}{|c|}{ Slow speed, Rotterdam-Shanghai } \\
\hline Suezmax & 39.05 & 120 & 583 & 523,271 & 0.8 & 13,114 & 263,825 & 14,500 & 363.8 \\
\hline Triple E & 30.4 & 150 & 583 & 463,704 & 0.6 & 18,000 & 343,100 & 18,000 & 339.8 \\
\hline \multicolumn{10}{|c|}{ Slow speed, Shanghai-Rotterdam-Shanghai } \\
\hline Suezmax & 67.8 & 120 & 600 & 972,281 & 0.825 & 13,114 & 263,825 & 14,500 & 631.9 \\
\hline Triple E & 61.0 & 150 & 600 & $1,096,212$ & 0.675 & 18,000 & 343,100 & 18,000 & 632.4 \\
\hline
\end{tabular}

Source: $[1,6,7,8,9]$, authors

As can be seen from the result, the operation of container vessels at slow steaming speed is more economical than at normal speed. The figures resulting from the calculation show that the costs per 1 TEU were reduced from around USD 900 to 630 . On the Shanghai-Rotterdam-Hamburg route, the difference was 270 USD/TEU. Despite a relatively significant reduction in transportation costs at 19 knots, it is important to consider the increase in shipping time by 9 days, as compared to transport at 23 knots. Fuel consumption follows an exponential function above around 18 knots. The figures show that the consumption increased by $105 \mathrm{t}$ /day in Suezmax ships and $135 \mathrm{t} /$ day in Triple-E ships. In Suezmax vessels, the shipping time was reduced from about 68 days to 59 days. Thanks to this reduction, the ship saves 9 days at a consumption of $120 \mathrm{t} /$ day and at the same time, there will be additional 59 days at a consumption of $105 \mathrm{t} /$ day. In Triple-E ships, the difference is even more marked: while saving 9 days at $150 \mathrm{t} /$ day, the ship travels additional 52 days at $135 \mathrm{t} /$ day. The total fuel consumption at slow steaming speed / normal speed is for Suezmax $8160 \mathrm{t} / 13275 \mathrm{t}$; for Triple-E class it is $9150 \mathrm{t}$ / $14820 \mathrm{t}$.

The total costs per 1 TEU on the cruise Shanghai-RotterdamShanghai for Suezmax and Triple-E class are eventually almost the same. There are differences in the individual cruising directions; however, the overall differences are marginal. The lower consumption of Suezmax ships is traded off by more frequent port charges on the route. Moreover, the higher number of ports called at contributes to a higher utilization of the vessel. It's the utilization - the container ship capacity utilization factor - that has a massive impact on the overall operating costs of the vessel. However, it is a very variable factor. On the maritime transport route considered, the utilization of vessels is distributed unevenly, the western direction being used more due to the heavy Asian export to Europe [10].

\section{Economic evaluation of operation}

In the calculations shown above, the most significant variables were the vessel's utilization factor and port charges. These two quantities have a considerable impact on the operational effectiveness of the two compared generations of container ships. As can be seen from the result, the operation of container vessels at slow steaming speed is more economical than at normal speed. The figures resulting from the calculation show that the costs per 1 TEU were reduced from around USD 900 to USD 630 . On the Shanghai-Rotterdam-Hamburg route, the difference was 270 USD/TEU. Despite a relatively significant reduction in transportation costs at 19 knots, it is important to consider the 
increase in shipping time by 9 days, as compared to transport at 23 knots. Fuel consumption follows an exponential function above around 18 knots, as can be seen in the chart in Fig. 1.

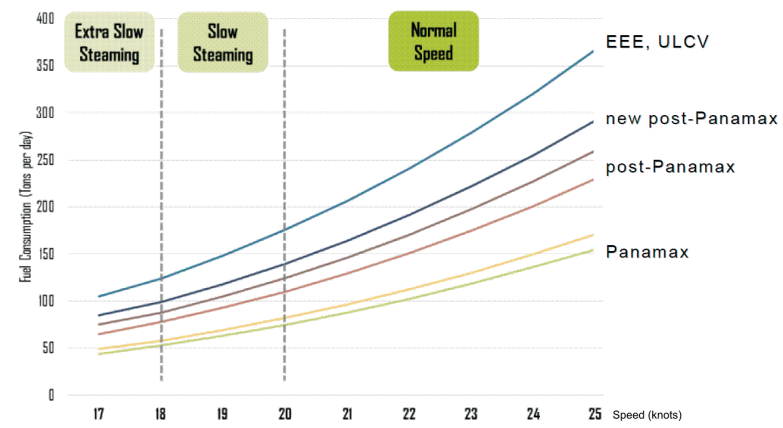

Fig. 1 Fuel consumption [tons per day] depending on speed and type of the container ship

Source: Hofstra University, New York [11]

The figures show that the consumption increased by 105 t/day in Suezmax ships and $135 \mathrm{t} /$ day in Triple-E ships. In Suezmax vessels, the shipping time was reduced from about 68 days to 59 days. Thanks to this reduction, the ship saves 9 days at a consumption of $120 \mathrm{t} /$ day and at the same time, there will be additional 59 days at a consumption of $105 \mathrm{t} /$ day. In Triple-E class ships, the difference is even more marked: while saving 9 days at $150 \mathrm{t} /$ day, the ship travels additional 52 days at $135 \mathrm{t} /$ day. The total fuel consumption at slow steaming speed / normal speed is for Suezmax $8160 \mathrm{t} / 13275 \mathrm{t}$; for Triple-E class it is $9150 \mathrm{t}$ / 14820 t. Since the crisis years of 2008 and 2009, the shipowners operate the ships at slow steaming speed on their longer distance routes despite the longer shipping time. This trend will probably last until a container ship drive is developed with an equal or lower consumption than the one vessels now have at a speed of about 19 knots.

On the route discussed, port charges play a considerable role. As opposed to the Triple-E vessels, the Suezmax container ships are more encumbered with port charges on the RotterdamShanghai route. This results in a difference of USD 24/TEU, where Triple-E ships at slow steaming speed are cheaper by this amount. In the opposite (western) direction, the number of calls at ports is the same for both vessels, and that's where longer idle times and larger dimensions of Triple-E become an important factor, due to which the costs per 1 TEU are in the western direction by almost USD 30/TEU higher than it is the case of the smaller Suezmax vessel.

The total costs per 1 TEU on the cruise ShanghaiRotterdam-Shanghai for Suezmax and Triple-E are eventually almost the same. There are differences in the individual cruising directions; however, the overall differences are marginal. The lower consumption of Suezmax ships is traded off by more frequent port charges on the route. Moreover, the higher number of ports called at contributes to a higher utilization of the vessel.
It's the utilization - the container ship capacity utilization factor - that has a massive impact on the overall operating costs of the vessel. However, it is a very variable factor. On the maritime transport route considered, the utilization of vessels is distributed unevenly, the western direction being used more due to the heavy Asian export to Europe. The results indicate that the costs per 1 TEU transported are the same provided that the vessels operate at slow steaming speed and their utilization is $82.5 \%$ for Suezmax and $67.5 \%$ for Tripple E.

In the calculation of operating unit costs per $1 \mathrm{TEU}$, only those factors are considered that have the greatest influence on the operating unit costs for the carrier (i.e. shipowner). These are those factors whose impact on operating costs is known and that can be quantified and included in the calculation without complex algorithms. However, more factors influence operating costs in reality, which shouldn't be forgotten. Their values are unstable and considerably variable depending on time and place. Due to their high variability and instability, those aspects of operating costs are not included in the calculation, which from accounting and economic perspectives actually create the operating costs. Some aspects of operating costs are not included in the calculation simply because they don't influence the operating costs to a significant degree and as such are negligible [12].

Costs in the transport sector can be considered from different perspectives. From the perspective of carriers, it is the actual costs incurred to purchase factors of production and to operate them. From the perspective of users of transport, i.e. customers of maritime carriers in this case (shipping agencies, end customers, surface carriers, etc.) it is the users' costs paid for maritime transport services [13]. There are also infrastructure related costs, i.e. costs of construction, modernization and maintenance of the transport network. These infrastructure related costs also include costs incurred to operate means of transport, i.e. external costs incurred to other entities.

Only the costs of the carriers, i.e. the carriers' own costs falling into their operating costs, are considered in the example calculation. These costs are then of significant influence on the users' costs, where the price for maritime transport is derived from the carrier's own costs to a great extent.

In the model calculation, the following items have been included:

fuel,

transit charges,

port charges,

daily operating costs of vessels.

These are items of own operating costs incurred to operate factors of production, i.e. in this case in the realization of the shipping process in maritime transport. However, there are other costs not included in this calculation that have an impact on the carriers' operating costs. It is the depreciation of tangible fixed assets and property insurance. 
In the depreciation of tangible fixed assets, the purchase price of factors of production is reflected, which were purchased for business purposes and to generate profit. This purchase price was paid before the actual operation of factors of production and has to be taken into consideration in calculating the operating costs. In this case, it is the different purchase prices of container ships that can influence the shipowners' operating costs.

When including the depreciation in operating unit costs, it is necessary to know the purchase prices of both ships and the approximate depreciation period of this kind of tangible fixed assets. The purchase price of a Suezmax container ship is approximately USD $110 \mathrm{M}$ [14]. The expected purchase price of the new generation Triple-E class ship is USD 190M [15] Assuming the depreciation period of a container ship is 30 years [16], it is possible to quantify the impact of depreciation on the unit costs per 1 TEU. If the depreciation costs are quantified based on data obtained from the calculations and data on purchase prices and depreciation period, the depreciation costs per 1 TEU are as follows:

Suezmax - USD 64 / TEU,

Triple-E class - USD 88 / TEU.

This calculation was made for the Shanghai-RotterdamShanghai route at the slower slow steaming speed. The calculations show that depreciation makes up for a difference in unit costs by USD 24 / TEU, these costs being higher for the newest generation of container ships due to the higher purchase price by approximately USD $80 \mathrm{M}$.

The impact of depreciation of fixed tangible assets (container ships) was not included in the calculation due to insufficient information on the ways and methods of depreciation in different countries in the world. Container ships are often registered in different countries than those where they were produced and where they perform the most shipping processes. It is not entirely clear which method of depreciation the container ship is subject to, i.e. straight-line or accelerated depreciation. In different countries, container ships can be parts of different depreciation groups leading to different lengths of depreciation periods. These depreciation rules depend on the legislation of the countries the ships fly the flag of. For this reason depreciation was not included in the calculation of operating unit costs and the amount of depreciation unit costs is indicative and is only to be considered from an overall perspective. Nevertheless, it is probable that the higher purchase price of the newest generation container ships is reflected in the operating costs to a certain degree, and as such it represents another cost item to be taken into consideration.

The ongoing trend of increasing the dimensions of cargo vessels together with an increasingly real threat of natural disasters which can endanger the container ship and its cargo are factors that lead to insurance companies increasing the premium. Threats like tornadoes, tsunami, ship collisions and other insured events occur more and more often nowadays. The price of the container ship itself together with the price of all the cargo it carries represent a significant amount, which can even be fatal for insurance companies. As a result, the premiums to insure vessels and cargo are continuously growing, which can also be reflected in the costs of the shipowner who will have to pay a higher premium to insure container ships with a capacity of 18,000 TEU as opposed to the shipowner who only has to pay for vessels with a smaller capacity.

\section{Economic effectiveness related to utilization}

As mentioned above, the utilization of a container ship is vital for the effectiveness of its operation. Vessel utilization and capacity are in terms of costs per 1 TEU closely related. The chart in Table 2 shows the costs expressed as a percentage depending on the capacity and utilization of the vessel compared to the costs related to a ship at full utilization, with a capacity of 14,000 TEU.

DNV Maritime and Oil \& Gas made a study of transport costs depending on the capacity and utilization of container ships. The results of the study are presented in Table 2, showing that if a container ship with a capacity of 18,000 TEU were to replace a ship with a capacity of 14,000 TEU to reduce costs, its utilization should not be lower by more than $10 \%$ compared to the utilization of the container ship with a capacity of 14,000 TEU. In such case, it is possible to reduce the costs per 1 TEU transported. Otherwise, if a sufficient capacity is not ensured, there is no point in producing ships with a capacity of 18,000 TEU.

Costs per 1 TEU transported depending on the utilization and capacity of vessels

Table 2

\begin{tabular}{|c|c|c|c|c|c|}
\hline & \multicolumn{4}{|c|}{ Vessel Size } \\
\hline & & 14000 TEU & $16000 \mathrm{TEU}$ & 18000 TEU & $21000 \mathrm{TEU}$ \\
\hline \multirow{6}{*}{ 苞 } & $100 \%$ & $100 \%$ & $97 \%$ & $91 \%$ & $89 \%$ \\
\hline & $95 \%$ & $105 \%$ & $101 \%$ & $96 \%$ & $94 \%$ \\
\hline & $90 \%$ & $110 \%$ & $106 \%$ & $101 \%$ & $98 \%$ \\
\hline & $85 \%$ & $117 \%$ & $112 \%$ & $106 \%$ & $103 \%$ \\
\hline & $80 \%$ & $123 \%$ & $119 \%$ & $112 \%$ & $109 \%$ \\
\hline & $75 \%$ & $131 \%$ & $126 \%$ & $119 \%$ & $116 \%$ \\
\hline
\end{tabular}

Source: Hofstra University, New York [11]

In practice, it is vital to find a utilization balance, where costs per 1 TEU are the same for both types of container ships compared. This balance is a milestone leading to the new giant container ships becoming more economically effective due to lower unit costs per one TEU transported.

What is considered is the actual utilization of Suezmax container ships cruising between Europe and Asia for several years already. Therefore, it is possible to establish their average utilization, which is $82.5 \%$ [17] on the Shanghai-RotterdamShanghai route. These real conditions serve as a basis for the 


\begin{tabular}{|c|c|c|c|c|c|c|c|c|}
\hline & $\mathrm{t}$ & $\mathrm{c}$ & $\mathrm{b}$ & $\Sigma_{\mathrm{n}}^{1}$ & $\mathrm{u}$ & $\mathrm{K}$ & $\mathrm{T}$ & $\mathrm{N}_{\mathrm{d}}$ \\
\hline Suezmax & 67.8 & 120 & 600 & 972281 & $\mathbf{0 . 9 5}$ & 13114 & 263825 & 14500 \\
\hline Triple E & 61.0 & 150 & 600 & 1096212 & $\mathbf{0 . 7 7 8}$ & 18000 & 343100 & 18000 \\
\hline \multicolumn{8}{|c|}{ Triple-E } & $\mathbf{5 4 8 . 8}$ USD \\
\hline Suezmax & 548.8 USD
\end{tabular}

Source: $[1,6,7,8,9]$, authors

calculation of the minimum utilization of Triple-E class ships, which shouldn't be lower than $67.5 \%$ for the costs per 1 TEU not to be higher than those of the smaller Suezmax ships. If the utilization of Suezmax ships is $82.5 \%$ and the utilization of Triple-E class is $67.5 \%$, the costs per 1 TEU transported are about the same, i.e. USD 632 [18]

For the new generation Triple-E class ships to be a real revolution in transport cost effectiveness, as they are claimed to be, their utilization should not fall below $67.5 \%$, where the utilization of their competitors - the Suezmax ships - amounts to $82.5 \%$ on average.

As the utilization of a cargo ship is a variable quantity depending on the current state of world stock markets, it is good to establish a minimum utilization rate for the situations where the ships would be utilized more. Specifically the Suezmax ships being used at $95 \%$, the minimum utilization rate that would keep the transport costs at least at the same level is $77.8 \%$ for the Triple-E class ship. This result is presented in Table 3 .

The calculations have produced results for the new types of container ships $(18,000 \mathrm{TEU})$, the utilization of which can be lower by a maximum of $15 \%$ compared to their competitors, i.e. the Suezmax container ships (with a capacity of 13,114 TEU).

\section{Conclusion}

The new types of container ships with a capacity of 18,000 TEU are suitable and effective to be used only on frequent maritime routes between large ports, where high volumes of goods are transported regularly regardless of the season. It should be those ports that are capable of serving this type of ships within 24 hours to prevent high port charges and idle times that are high due to the ship's dimensions. Ports suitable for the new types of container ships will have to be equipped with an adequate shipping system considering the container ship holds and more importantly, its infrastructure will have to be of sufficient capacity to ensure enough goods for loading and their fast moving after unloading for both the port and the berthing ships.

There are not so many such ports at the moment, and that is why it is advisable to operate Triple-E class ships on the Asia-
Europe-Asia route between the ports of Rotterdam, Bremerhaven, Shanghai, Ningbo and Hong Kong. The Triple-E class ships are only operated more effectively compared to regular ships with a capacity of slightly more than 13,000 TEU provided that the utilization of the higher capacity vessels is lower by a maximum of $15 \%$. This difference is illustrated by the calculations above. The results imply that it is advisable to operate Triple-E class ships in such seasons and on such routes, where there is a realistic chance to utilize the ship to such extent that this utilization would not be lower than by $15 \%$ compared to operating a smaller container ship already mentioned in this paper and in [1,2 and 3].

In the event the shipping volumes will continue to grow and the ports on the Asia-Europe route will adapt to them continuously, the Triple-E class ships will be used more frequently and the smaller vessels they will substitute will be operated on less frequent maritime routes, where in turn the ports will have to adapt to their dimensions they are not designed for at the moment. These developments of maritime business becoming reality in the future, the transport costs will really be significantly reduced and Triple-E class ships' capacities will be used in full. However, before this happens it is to a certain extent a marketing strategy of large shipowner companies producing larger and larger container carriers, where at the same time they face the risk of the current maritime business situation, in which these high capacity ships cannot be utilized to an extent that would dramatically reduce unit transport costs.

\section{Acknowledgment}

Thispaperhasbeen supported as part of theSG540001/20/51030 "Student grant competition“, CZ.1.07/2.3.00/20.0226 "Support networks of excellence for research and academic staff in the field of transport (DOPSIT)“ and CZ.1.07/2.4.00/17.0107 "Support of short term attachments and skilful activities for innovation of tertiary education at the Jan Perner Transport Faculty and Faculty of Electrical Engineering and Informatics - University of Pardubice“ projects. These projects have been co-financed by the European Social Fund and state budget of the Czech Republic. 


\section{References}

[1] SIROKY, J., DUBEN, J.: The Effectiveness of Large Container Carriers in Maritime Transport (in Czech), Perner's Contacts, University of Pardubice, vol. IX., No. 1, April 2015, pp. 170-179, ISSN 1801-674X, Accessible at: http://pernerscontacts.upce.cz/ 34_2014/Siroky.pdf.

[2] DUBEN, J.: The Transport Efficiency of Large Container Carriers in Maritime Transport (in Czech), diploma thesis, University of Pardubice, 2013.

[3] SIROKY, J.: The New Large Container Carriers and Their Operational Effectiveness in Logistics Chains, Applied Mechanics and Materials, vol. 803, pp. 76-81, November 2015.

[4] Triple-E Class Container Ships, Denmark. In: Ship-technology.com [online]. 2014 [cit. 2014-05-07]. Accessible at: http://www. ship-technology.com/projects/triple-e-class/.

[5] Ship sizes. Maritime Connector [online]. [cit. 2014-11-17]. Accessible at: http://maritimeconnector.com/wiki/ship-sizes/.

[6] GOVERNMENT OF HONG KONG SPECIAL ADMINISTRATIVE REGION. Port Benchmarking for Assessing Hong Kong's Maritime Services and Associated Costs with other Major International Ports [online]. [cit. 2014-09-07]. Accessible at: http://www. mardep.gov.hk/en/publication/pdf/port_bm_study.pdf.

[7] PORTS.COM. Ports.com: Sea Route \& Distance [online]. 2010 [cit. 2014-09-22]. Accessible at: http://ports.com/sea-route/

[8] Suez Canal Pricing Forecast 2005 - 2025: Final report [online]. 2005 [cit. 2014-09-28]. Accessible at: http://www.pancanal.com/ esp/plan/estudios/0284.pdf.

[9] Sea distances: Voyage calculator [online]. [cit. 2013-09-22]. Accessible at: http://seadistances.com/

[10] Marine Engineering. National University of Athens [online]. [cit. 2014-11-18]. Accessible at: Athenshttp://www.naval.ntua.gr/ Presentations/Conta inership\%20NTUA\%202005.pdf.

[11] HOFSTRA UNIVERSITY: The Geography of Transport Systems [online]. New York. [cit. 2013-11-18]. Accessible at: http://people. hofstra.edu/geotrans/eng/ch8en/conc8en/ fuel_consumption_containerships.html

[12] GRIMSTAD, A., NEUMANN-LARSEN, E.: Ultra-large Container Vesselscan the Economy of Scale be Quantified. [online]. 21.3. 2013 [cit. 2013-10-06]. Accessible at: http://www.dnv.com/industry/maritime/publicationsanddownloads.

[13] NOVAK, J., CEMPIREK, V., NOVAK, I., SIROKY, J.: Intermodal Transport (in Czech), University of Pardubice, 2015, 978-807395-948-7.

[14] MOSTAFA, K.: Big Ships a Big Wory for Ports. Drewry: Maritime Research [online]. 27/10/2013 [cit. 2013-11-03]. Accessible at: http://ciw.drewry.co.uk/portdevelopments/big-ships-a-big-worry-for-ports/\#.UnYfIVN7Sd8.

[15] MAREK, O., BARTOSEK, A.: Logistics Operations within the Transshipment in the Container Ports (in Czech) [online], November 2011 [cit. 2013-11-09]. Accessible at: http://pernerscontacts.upce.cz/23_2011/Marek.pdf

[16] APL. Equipment Specifications: Standard Containers [online]. 2015 [cit. 2015-11-15]. Accessible at: http://www.apl.com/ equipment/html/equipment_specs_standard.html

[17] JAGELCAK, J., DAVID, A., ROZEK, P.: Sea Containers (in Slovak), EDIS: University of Zilina, 2010. ISBN 978-80-554-0207-9.

[18] UNCTAD. In United Nations Conference on Trade and Development. Implementation of multimodal transport rules [online]. Geneva: UNCTAD, 2002 [cit. 2011-04-10]. Accessible at: http://www.unctad.org/en/docs/posdtetlbd2.en.pdf. 